\title{
EN TORNO A LAS FORMAS DESCOMPUESTAS
}

\author{
Ma ViCTORINA CREGo GARCÍA \\ (Universidade de Santiago de Compostela)
}

\begin{abstract}
The approachment to a series of more or less fossilized configurations has showed the existence of general profile properties applicable to complex, direci lexis. It has also showed particular characteristics of fixed constructions organized around verbs of movement (followed by direct structures, prepositional and adverbial). Formal or morphological properties as the absence of determiners, sintactic properties as the sintactic incorporation or recessive process, and semantic properties as the more or less opaque nature of lexematic components have lead us to a series of constants that help us, at least, to characterize these linguistic units. Needless to say that we are dealing with more or less fixed structures that make sense in a gradual frame of analysis in which more or less prototypical propierties of these complex lexis are used, and therefore, complex lexis that are more or less prototypical.
\end{abstract}

\section{Introducción}

La detección e individualización de sintagmas complejos de valor unitario del tipo de poner en evidencia y dar miedo' en el ámbito del

\footnotetext{
' Como, de alguna manera, se puede deducir del inicio de este trabajo, el objetivo que nos hemos marcado es la descripción de formas complejas compuestas de verbo y de un elemento nominal, del tipo de darse cuenta, o de verbo y un constituyente prepositivo-nominal de la naturaleza de poner en entredicho. Esto significa que no abordaremos unidades complejas que remitan a una estructura sintáctica oracional o casi-oracional como los proverbios, adagios o dichos y construcciones de la naturaleza de Tejer y destejer, coser y cantar, en un abrir y cerrar de ojos (cfi. Castillo Carballo, 1997-1998 y Wotjak, 1985: 215-216).

Asimismo queremos hacer notar que entendemos los términos complejos constituyente prepositivo-nominal o constituyente nominal en un sentido genérico dado que, aunque suelen referirse a sustantivos (con o sin determinante o modificador) precedidos o no de preposición, respectivamente ( $v . g r$. , darse cuenta, llevar a cabo, llevar a buen término), en ocasiones nos cncontraremos con entidades adverbiales, adjetivas o pronominales del tipo de echar de menos, echar abajo, pasar por alto o ir a lo suyo.
} 
español han sido relativamente tardías, habida cuenta de que se trata de un proceso lingüístico con raíces en el latín ${ }^{2}$ y desarrollo posterior en las diversas etapas de la lengua española, además de en otras lenguas neolatinas como el lrancés ${ }^{3}$.

Estas entidades lingüísticas encuentran explicación en el marco del discurso repetido de Coseriu (1981: 297-302) dado que están sometidas a un proceso de lijación léxica y formal que otorga escaso, si no nulo, margen de maniobra a variaciones léxicas y formales ${ }^{4}$. «Sus elementos no son lingüísticamente «estructurables» porque, en la medida en que son fijos, no son sustituibles («conmutables») y, por consiguiente, no participan en oposiciones funcionales actuales» (Coseriu, op. cit:: 299) ${ }^{5}$. Según Dubsky (1966: 195); retomando sus propias palabras:

Les traits qui remiten a un mecanismo lingüístico diferente al representado por la tradicional composición caractérisent les tournures verbo-nominales au point de vue formel $[\ldots]$ et leur caractère sémantique en font bien un groupe à part que l'on peut difficillement inclure dans le cadre des syntagmes dits composés. En effet, tandis que dans les cas des syntagmes composés il y a nécessairement juxtaposition des composants qui résulte de la complexité de la réalité extralinguistique que les syntagmes composés veulent exprimer, les tournures verbo-nominales, qui en diffèrent aussi bien par leur forme que par leur signification et fonction, paraissent être le résultat d'un autre processus: au lieu d'arriver à la formation du syntagme par la composition d'éléments résultant de l'analyse de la réalité extra-linguistique complexe, ici on part de la réalité extra-linguistique simple pour en arriver à la création d'un syntagme complexe. $L$ 'analyse ne vise pas ici les diflérents aspects de la réalité extra-linguistique pour les traduire dans une expression complexe, un syntagme composé, mas bien au contrairc, à l'idée unique simple correspond ici un syntagme qui est complexe par sa forme, tout en conservant la signification unique simple. C'est pourquoi il nous semble utile

\footnotetext{
${ }^{2}$ Harvcy (1968) atribuye también a influjo árabe la tendencia analítica que ilustran estas formas complejas.

${ }^{3}$ Proceso que es extrapolable a lenguas no romances como el inglés y el alemán y, en general, a las lenguas de la Europa occidental (cfr. Polák, 1949-51), además de a lenguas orientales.

${ }^{4}$ A este respecto vid. Zuluaga (1975).

${ }^{5}$ Corpas Pastor (1997: 19-20) nos remite a cinco rasgos para la caacterización de las unidades fraseológicas en general: (i) expresiones formadas por varias palabras; (ii) institucionalizadas; (iii) estables, aunque en diverso grado; (iv) poseedoras de ciertas particularidades sintácticas y scmánticas; $y$, por último, (v) con mayor o menor posibilidad de variación de sus clementos integrantes.
} 
de parler ici non pas de la composition et du syntagme composé, mais bien plutôt du procédé de décomposition.

La incorporación en los estudios gramaticales y léxicos de estos complejos sintagmáticos, denominados comúnmente formas descompuestas", locuciones verbales, lexías complejas $^{8}$ o formas incorporadas", ha supuesto, además de una nueva distinción lingüística, la necesidad de recurrir a una serie de criterios o rasgos individualizadores de cstos complejos verbo-nominales de valor unitario.

Estos criterios de perfíl nocional, formal o sintáctico, al tiempo que dejan al descubierto propiedades que se deben tener en cuenta para establecer oposiciones o distinciones lingüísticas, en muchas ocasiones conducen a un enmarañamiento teórico y descriptivo más que a una clasificación relativamente bien delimitada. Con posterioridad veremos que es posible que la única vía de análisis mínimamente homogénea y coherente de este tipo de unidades sea una vía asociada a un punto de vista gradual o jerarquizado en el que hay que asumir la dicotomía básica plano semántico / plano sintáctico, por tanto, unidad léxica / unidad sintáctica, con el auxilio necesario que aporta la dimensión formal o morfológica.

En principio, presentaremos los tres niveles analíticos que se suelen adoptar para abordar las formas descompuestas, niveles que se corresponden con los parámetros o criterios delimitativos que, de forma más o menos unívoca y nítida, contribuyen a individualizar la parcela estructural que estos complejos verbo-nominales ocupan ${ }^{10}$. Este acercamiento inicial abarcará los apartados 1 y 2 y se realizará tomando en consideración formas descompuestas directas e indirectas, en tanto que en el apartado tercero nos centraremos en la tipología indirecta a partir de una base de datos a la que hemos tenido acceso (vid. infra nota 34).

\section{Niveles de análisis de las formas descompuestas}

\footnotetext{
Vid. Dubsky $(1963,1965,1966)$.

${ }^{7}$ Vid. Bernard (1974) y Gaatone (1981).

"Vid. Cano Aguilar (1981: 51-52, 104-105, 125; 1984: $211-212 ; 1985: 90)$.

"Crr. Bosque (1996), Lazard (1984: 275-276) y Masullo (1996). Otras etiquetas como perífrasis verbal (cfr. Menéndez Pidal, 1944-46: II, 152 y Polák, 1949-51) y forma analíica (cfi. Yllera, 1980: $\$ 0.1$ ) han tenido menos fortuna, posiblemente por la intromisión de la primera en el ámbito de las tradicionales perífrasis verbales y por la naturalcza excesivamente amplia y vaga de la segunda. En nuestro caso, aunque en este trabajo utilizamos la mayor parte de estas etiquetas para remitir a la misma realidad lingüística, mostramos una clara preferencia por el término forma descompuesta.

${ }^{10}$ En Corpas Pastor (1997: 89.90) se pueden encontrar criterios que aquí no abordaremos.
} 


\subsection{Nivel semántico}

En opinión de Dubsky (1963: 32) estamos ante

construcciones formadas por un verbo más o menos desprovisto de significado y transformado en instrumento gramatical, cuya función es idéntica a la de los morfemas que expresan la persona, el número y el tiempo, y un substantivo de actor o acción [...].

Recurre, como hemos comprobado anteriormente, al término forma descompuesta porque se trata de una etiqueta que

tiene $[\ldots]$ la ventaja de subrayar el proceso de descomposición que es la base y el principio constitutivo de las construcciones «verbo» + «nombre»: en vez de componerlas de sus componentes - verbal y nominal-, el sujeto que habla parte, al revés, de la idea compleja de acción y llega a su expresión descompuesta, cuyo núcleo es el sustantivo [...].

Desde el punto de vista semántico se considera que las formas complejas tienen un valor unitario emanado de la conjunción de los constituyentes que las integran, de manera que las formas complejas más lexicalizadas se asocian al carácter opaco, figurado o traslaticio de sus componentes - la tradicionalmente denominada idiomaticidad-, en particular del constituyente nominal o prepositivo-nominal:

(1) a. Dar a luz

b. Tener lugar (con la acepción 'ocurrir')

c. Poner en tela de juicio

d. Poner en entredicho

e. Sacar a colación

f. Sacar de quicio

g. Sacar punta

h. Sacar pecho

i. Llevar a cabo

j. Caer en la cuenta

k. Echar de menos

Sc trata de una traslación semántica «generalizadora» del componente nominal, con pérdida de la dimensión referencial individualizadora propia de este componente a favor de la constitución de un valor complejo perifrástico en el que entran el constituyente verbal que aporta las categorías morfológicas y el constituyente nominal o prepositivo-nominal que proporciona la información léxica. 
La parte nominal o prepositivo-nominal de estas entidades «más» lexicalizadas ofrece un uso especializado o estereotipado, es decir, que su uso independiente es prácticamente nulo (v.gr., tela de juicio, entredicho, colación o manifiesta, en el nivel semántico, un valor inexistente en el complejo (y.gr., quicio, cabo, cuenta, luz, tela de juicio, colación), mientras que las «menos» lexicalizadas o fijadas mantienen, en cierta medida, la individualidad semántica o denotativa de sus constituyentes nominales ${ }^{\prime \prime}$, dado que conservan en mayor o menor grado la dimensión semántica propia de los usos libres:
(2) a. Poner de moda
b. Poner en duda
c. Poner lin
d. Poner remedio
c. Ir de vacaciones
[. Llevar a buen término
g. Tener miedo
h. Tener sed
i. Hacer mención
j. Hacer alusión
k. Dar respuesta

Por tanto, la existencia de tonalidades intermedias o la inexistencia de un comportamicnto sistemático en el plano semántico evidencia, de inmediato, la no idoncidad de este para establecer demarcaciones lingüísticas en el ámbito de las lexías complejas si no se apoya en mecanismos de perfil sintáctico y formal. Todas ellas tienen en común el proceso lingüístico centrílugo de descomposición que ilustran, aun cuando a través de tres Cormas descompucstas como tener miedo (meter miedo), sacar pecho y sacar a colación podemos detectar una evolución decreciente en relación con la naturaleza transparente o literal de los elementos que las conforman.

No obstante, existen una serie de principios generales anclados en el nivel nocional que resultan útiles para, por lo menos, describir el comportamicnto de las formas descompuestas. En este sentido, es obvio que los componentes verbales que integran la parte flexiva de estos complejos

\footnotetext{
"Dubsky (1966: 194) diferencia locuciones verbales de formas descompuestas en virtud de una distinción de naturaleza semántica; de tal forma que en las primeras integra complejos verbo-nominales del tipo de casser sa pipe (mourir) y tomar el pelo (en francés se moquer de q.) cuyos componentes se fusionan para dar lugar a un sintagma de significado unitario que no tiene nada que ver con el significado de cada uno de sus componentes, en tanto que el valor significativo de las formas descompuestas es el resultado de la suma de los significados de sus dos constituyentes (v.gr., avoir un sourire $=$ sourire, dar un grito $=$ gritar, to give a jump $=10$ jumip).
} 
son entidades verbales que han perdido parte, si no la totalidad, del contenido que actualizan en las configuraciones autónomas, dando lugar, en muchas ocasiones, a los denominados verbos auxiliares o semiauxiliares ${ }^{12}$, verbos soporte ${ }^{1.3}$ o verbos ligeros o livianos ${ }^{14}$.

Ofrecen el comportamiento prototípico de estos subtipos verbales un conjunto de verbos, relativamente reducido en contraste con el carácter menos cerrado de las entidades nominales, como dar, tener y hacer ${ }^{15}$. No obstante, admite que existen otros verbos soporte de la naturaleza de prestar (asistencia, atención, auxilio), sacar (partido, fruto, provecho) o tomar (tierra, parte) que, en muchas ocasiones, muestran un comportamiento fronterizo con respecto a los verbos plenos. en formas descompuestas directas de la naturaleza de dar respuesta, tener miedo o hacer hincapié o entidades verbales como echar, poner o sacar ${ }^{16}$ en formas descompuestas directas como echar pestes, poner remedio y sacar partido o indirectas del tipo de echar de menos, poner en marcha y sacar de quicio.

Estos verbos, incrustados en los complejos mencionados, adquieren una dimensión básicamente instrumental en tanto en cuanto sirven para transportar morfemas flexivos de tiempo, persona, número, voz y aspecto en detrimento de una autonomía semántica que no poseen, dado que adquieren un valor genérico e impreciso que se ve arropado $\mathrm{y}$, por ende modificado, por el contenido nuclear de la forma nominal, y de una autosuficiencia sintáctica que les permita regir los complementos que rigen en las conlïguraciones autónomas, puesto que no tienen la capacidad de seleccionar argumentos. En consecuencia, constituyen predicados livianos defectivos en el nivel temático ya que, en términos de Masullo (1996: 176),

\footnotetext{
12 Cfi. Dubsky (1963), Harvey (1968) y Menéndez Pidal (1944-46: II, \$152).

${ }^{1.3}$ Cfi. Guillet (1986: 97-98), Leclère (1990: 113) y Melero y Gracia (1990).

${ }^{1+}$ Cfr. Bosque (1996: 46-48) y Masullo (1996: 173).

${ }^{15}$ Bosque (1996: 47) resalta el carácter productivo de estos verbos soporte cn el ámbito del cspañol:
}

TENER: miedo, cura, lugar, calor, conciencia, razón, valor, sueño, sed, hambre, tondencia, sucrte, miedo, capacidad, ardor, deseo, aptitud, voluntad.

DAR: niedo, envidia, pena, sueño, lástima, alegría, asco, hambre, frío, permiso, satisfacción, carta blanca, orden, batalla, albergue, cuenta, guerra.

HACER: uso, fuego, sitio, ilusión, gracia, caso, frío, sol.

16 Los verbos de movimiento también funcionan como verbos soporte de estructuras descompuestas directas del tipo de echar (mano, el guante, pestes, cuenta, la culpa, raices, una mirada), meter (mamo, baza), pasar (revista), poner (orden) y sacar (provecho, partido, plesto). Asimismo, queremos hacer notar que en las estructuras descompuestas indirectas constituyen verbos soporte prototípicos entidades verbales de movimiento como sacar (de las casillas, a colación) y poner (en duda, en entredicho), además de otras que, posiblemente, lo son menos como caer (en la cuenta, en saco roto), echar (de menos), ir (de vacaciones), llevar (a buen término, a cabo), pasar (por altos20), salir (al paso), venir (a cuento) o volver (a las andades) (vid. infra apdo 3 ). 
carecen de grilla o red temática «debiendo, por tanto, depender de un elemento predicativo [la entidad nominal o prepositivo-nominal que los sigue] para poder marcar temáticamente los argumentos de la oración». En palabras de Melero y Gracia (1990: 657):

La noción de verbo soporte va muy ligada a la de nombre predicativo. La idca es que, en estas construcciones, al estar el verbo semánticamente vacío, la predicación reside en el nombre. Esto implica por un lado, que el contenido scmántico de la expresión depende sólo del componente nominal y además, que dicho componente impone restricciones semánticas a los argumentos de la predicación y asigna los papeles temáticos correspondientes.

Para que todo ello sea posible es condición indispensable que el nombre sea predicalivo.

Por tanto, es el sustantivo, cuyo perfil semántico suele incluir los rasgos $[+ \text { abstracto }]^{17}$ y $\left[+\right.$ continuo $^{18}$, el que centraliza la relevancia semántica y comunicativa del complejo verbo-nominal (vid. Ramos Méndez, 1989: 343), crigiéndose en el componente que marca las restricciones semánticas de los clementos que lo siguen.

\subsection{Nivel sintáctico}

El nivel sintáctico se encuentra vinculado a la ausencia de autonomía sintáctica de los componentes del complejo sintagmático que constituyen una construcción descompuesta frente a la autonomía sintáctica que preside a los constituyentes de las estructuras no descompuestas ${ }^{19}$. Esto significa

\footnotetext{
${ }^{17}$ En opinión de Mithun (1984: 863): «Since speakers are usually more interested in human beings (and perhaps animals) than in inanimate objects, animate $N$ 's are often not incorporated at all. If they are, it is usually [...] where they are highly generic, as in 'to be a good person'. $N$ 's reflecting individual patients of $V$ 's such as 'to be sick' or 'to die' are rarely if ever incorporated». También considera que: «Relatively generic N's are already being used to qualify V's, and to keep reference straight within discourse. Languages generally do not incorporated proper $\mathrm{N}$ 's, since they are not sufficiently generic to narrow the scope of $\mathrm{V}$ 's in a useful way; however, most incorporating languages do incorporate such terms as 'body' and 'mind', sinec they provide a device for qualifying V's which pertain to the physical or mental aspect of a person or animal» (op. cit:: 864).

is Aunçue el rasgo [+discontinuo] aparece en complejos como dar albergue, pedir consejo u obtener carta blanca (cfi. Bosque, 1996: 48), la tendencia general es que los componentes nominales scan [+continuos] del tipo (tener) miedo, (dar) lástima o (hacer) ilusión.

1. Alcina y Blecua (1975: 881-882) distinguen, en el ámbito de los elementos regidos, clementos regidos de término lijo ( $v . g r$., echar de menos), en los que preposición y término de lil preposición constituyen elementos fijos, y elementos regidos de término variable (v.gr..
} 
que, si bien hemos adoptado el término forma descompuesta teniendo en cucnta la naturaleza analítica de las entidades a las que da nombre (cfr. poner en evidencia), en contraste con el perfil sintético del verbo simple (cfr. evidenciar), el proceso sintáctico que se puede observar es el de la «incorporación», puesto que se trata de un mecanismo sintáctico recesivo en el que el componente nominal o prepositivo-nominal deja de funcionar como actante. Tal y como ilustra García-Miguel (1995: 98), se da la siguiente evolución lingüística:

$$
\mathrm{N}-\mathrm{V}-\mathrm{N} \rightarrow \mathrm{N}-[\mathrm{VN}]^{20}
$$

materializada a través de las secuencias:

(3) a. Mi hermano me dio todo el dinero que le quedaba - Me da miedo tu actitud

b. Puso la caja en la parte superior del armario - Puso en duda tus argumentos

Para constatar la naturaleza unitaria, compacta, en definitiva no autónoma, de los constituyentes de dichas formas descompuestas se suele aludir a la posibilidad de conmutación de tales entidades por un verbo simple que mantenga gran parte de su perfil semántico y funcione sintácticamente en el hueco que aquellas cubren (cfr. Cano Aguilar, 1981: $51-52,104-105,125)$ :

(4) a. Poner en evidencia $\rightarrow$ evidenciar

b. Poner de manifiesto $\rightarrow$ manifestar

c. Tener miedo $\rightarrow$ temer

d. Dar respuesta $\rightarrow$ responder

e. Hacer colección $\rightarrow$ coleccionar

f. Hacer uso $\rightarrow$ usar

g. Hacer comentarios $\rightarrow$ comentar

Esta equivalencia significa que las formas descompuestas realizan la misma función sintáctica que el verbo simple, de modo que «la función predicado puede estar desempeñada en español al menos por dos categorías: verbo y forma descompuesta» (Folgar, 1988: 301).

abundar en oro), en los que la preposición es el único constituyente exigido por el verbo y, por tanto, el único componente fijo de la estructura.

${ }_{201}$ En las formas descompuestas directas se da paso a un grado de transitividad 0 (clr. Hopper y Thompson, 1980) a tenor de la integración en el predicado del significado léxico del complemento directo, aun cuando no existe integración fonética ni morfológica (vid. infra apdo 2). 
No obstante, csto no quiere decir que a cada forma descompuesta se le pueda atribuir unívocamente un verbo simple del tipo de la serie de cjemplos (4) (cir. llevar a buen término, volver a las andadas, sacar a colación, ctc.), sino que esas correspondencias entre forma compleja y verbo simple que suclen compartir la misma raíz (la entidad nominal y el verbo simple, respectivamente) no hacen sino ratificar la naturaleza unitaria de tales complejos verbo-nominales.

Asimismo se articulan una serie de pruebas sintácticas de base transformacional para probar la naturaleza autónoma o compleja de las cntidades linguísticas abordadas. Se trata de pruebas que operan con configuraciones interrogativas, ecuacionales y de sustitución pronominal (dirceta o indirceta) que muestran la naturaleza más o menos autónoma de la cntidad nominal o prepositivo-nominal. De esta forma, podemos comprobar que fómulas descompuestas como dar miedo, hacer hincapié o poner en entredicho no tolcran la extracción del constituyente nominal o prepositivonominal a través de las estructuras interrogativas:

(5) il. *QQué te da su actitud? Miedo

b. ¿QQué hiciste? Hincapié en ese asunto

c. * ¿En qué pusiste ese aspecto? En entredicho

Tampoco permiten la estructura ecuacional:

(6) a. *Miedo es lo que me da su actitud

b. *Hincapié en ese asunto es lo que hiciste

c. *En cntredicho es en lo que pusiste ese aspecto

Y, linalmente, también es inviable el proceso de sustitución pronominal aplicado a tales entidades:

(7) a. iTe da miedo su actitud? Sí, *me lo da

b. ¿Hiciste hincapié en ese asunto? Sí, *lo hice en él

c. ¿Pusiste en entredicho ese aspecto? Sí, *lo puse en eso

No obstante, si aplicamos estos tests a formas incorporadas como tener frío (miedo, sed) o tener agallas nos encontramos con que la mayoría de las secuencias resultantes son, por lo menos, más aceptables que las anteriores:

(8) a. ¿Qué tienes? Frío (miedo, sed)

b. Lo que tengo es frío (miedo, sed)

c. ¿Tienes frío (miedo, sed)? Sí, lo tengo

(9) a. ¿Qué tiene tu hermano? Agallas

b. Lo que tiene tu hermano son agallas

c. ¿Tu hermano tiene agallas? Sí, las tiene 
Este comportamiento posiblemente está vinculado al hecho de que el verbo tener mantiene el mismo valor general de estatismo que posee en las estructuras no incorporadas del tipo de:

(10) Tengo mucho dinero en el banco,

lo que marca cierta continuidad en el estrato sintáctico entre las estructuras no incorporadas y las incorporadas con respecto a las pruebas transformacionales antes utilizadas. Frente a esta entidad verbal, otros verbos como hacer o dar se distancian de forma más nítida del valor de acción prototípico de las estructuras transitivas cuyos complementos directos son efectuados y afectados ${ }^{21}$, respectivamente:

(11) a. Hizo los ejercicios correctamente

b. Les di todos mis ahorros a mis padres

Que, en el caso de tener, el comportamiento relativamente semejante en sus usos complejos y autónomos en relación con las pruebas vertebradas signifique que los complejos verbo-nominales de tener remiten a un grado de incorporación sintáctica menor que el de los encabezados por entidades verbales como dar o hacer, aunque la incorporación semántica sea hasta cierto punto semejante, es una posibilidad pendiente de desarrollo y resolución. En este sentido, Masullo (1996: 191), al aplicar una prueba de extracción mediante la cláusula relativa, comprueba que, así como las preposiciones livianas no toleran la extracción (infra (12a-c)), sí es posible aplicar este mecanismo a determinados verbos livianos (infra $(12 \mathrm{~d}-\mathrm{e})$ ):

(12) a. *El traje de que se vino era muy caro. (Cf. Se vino de traje)

b. *Las vacaciones de que estamos son fantásticas. (Cf. Estamos de vacaciones)

c. *El desacuerdo en que estábamos era completo. (Cf. Estábamos en desacuerdo)

d. El miedo/hambre que tengo es terrible

e. La alegría que me da la noticia es enorme

\footnotetext{
${ }^{21}$ Por tanto, son configuraciones más prototípicamente transitivas que las estructuras transitivas de tener que, siguiendo los presupuestos de Hopper y Thompson (1980), remiten a un grado de transitividad bajo. En consecuencia, parece que existe un paralelismo claro en cuanto al grado de transitividad de tener en construcciones libres y complejas (bajo en ambas, aunque más, por supuesto, en las segundas), lo que justifica la continuidad en el estrato sintáctico transformacional. En contrapartida, el contraste entre las estructuras libres y complejas de hacer y dar es claro, ya que en las primeras materializan una transitividad alta o prototípica y en las últimas una transitividad muy baja o nula.
} 


\subsection{Nivel morfológico}

Finalmente, en lo que atañe al estrato morfológico, se suele hacer hincapié en que el proceso de lexicalización en que se encuentran inmersos cstos complejos en mayor o menor medida está asociado a la ausencia de determinantes y de modificadores y que, cuando estos últimos aparecen, en general están situados en posición prenominal, mientras que los determinantes integrantes de estos complejos pertenecen a los paradigmas de valor más genérico y menos marcado, fundamentalmente artículo definido o indefinido (en orden decreciente de uso), y posiblemente han perdido valor opositivo a tenor del mecanismo de lexicalización en el que están involucrados:
(13) a. Ir a las manos
b. Salir al paso
c. Salir a la luz
d. Echar una mirada
c. Meter en un berenjenal

Además, es típico de las formas descompuestas el bloqueo de la variación numérica en favor del singular, parte no marcada del binomio singular-plural, y la neutralización de la oposición genérica a través del masculino (polo no marcado de la categoría género), neutralizaciones materializadas, en ocasiones, mediante la ausencia de determinantes y modificadores con los que concordar, aunque no siempre sucede esto, tal y como constatan los complejos en los que aparece un determinante más o menos lexicalizado portador de los morfemas de género femenino y/o número plural ${ }^{22}$ :
(14) a. Dar una bofetada
b. Echar la culpa
c. Volver a las andadas

No obstante, tal y como admite Zuluaga (1975: 229), «los elementos fijos en dichas expresiones [que indican género y número] carecen de valor opositivo; p.ej., el plural de la fórmula de saludo buenas tardes no indica

\footnotetext{
${ }^{22}$ La neutralización del género y del número es palpable en aquellos complejos cn los que el componente nominal no se combina con ningún determinante o modificador, en tanto que el número marcado, cl plural, y el género marcado, el femenino, todavía aparecen en complejos del tipo de echar pestes, echar raices, meterse en camisas de once varas. Por supuesto, los adverbios no actualizan nunca género ni número (v.gr., venirse abajo, echar abajo, ir (adelante).
} 
propiamente una cuantificación semántica (pluralización) por oposición a la combinación en singular buena tarde».

Asimismo, la ausencia de actualizadores supone la concepción del componente nominal como una clase genérica y no como una entidad individualizada y referencial ${ }^{23}$, de ahí que este constituyente remita en la mayoría de las ocasiones a los rasgos [+abstracción] y [+continuidad] que no designan ningún referente que exista con independencia del proceso sino una propiedad reconocida socialmente y general ${ }^{24}$ (cfr. tener hambre, buscar piso) o una dimensión significativa y funcional cercana al valor predicativo del verbo (poner en entredicho, venir a cuento). Según García-Miguel (1995: 102) en construcciones del tipo de:
(15) a. Hacer novillos
b. Tener micdo
c. Da micdo tener que amoldarse
d. Pegar gritos

corresponde al verbo soporte la indicación del tipo general de proceso (por ejemplo, dinámico / estático), pero es el nombre el que por lo demás funciona como predicado semántico de la cláusula especificando el tipo de relación que une a los actantes (compárese el «proceso material» hacer una silla con el «proceso verbal» hacer mención de algo, o los «procesos mentales» clar miedo, tener miedo) y el que selecciona las características semánticas de los actantes (compárese Los nuevos cambios están dando muchos problemas con * Los nuevos cambios están dando un paseo). La fijación morfológica —unida a un proceso de lexicalización total ${ }^{25}$ - es evidente en complejos del tipo de poner de relieve, venir a cuento, meter baza, pasar revista o darse cuenta, en los que la ausencia de actualizadores y modilicadores ${ }^{26}$ se suma a la neutralización de las distinciones genéricas y numéricas. En palabras de Zuluaga (1975: 234): «Mientras mayor sea el número de elementos fijos de una expresión, más elevado será el grado de

\footnotetext{
${ }^{2.3}$ En el seno de la que considera Masullo (1996: 176) defectividad estructural de la proyección nominal que convierte los elementos nominales o prepositivo-nominales en clementos predicativos, pero no referenciales.

${ }^{24}$ Vid. Moreno Cabrera (1991: 497-499).

25 El proceso de lexicalización se halla vinculado, además de a la inmovilidad formal cel constituyente nominal, al carácter opaco del significado resultado de la unión de verbo y entidad nominal, de tal forma que la lexicalización es más clara en aquellas formas descompuestas en las que el significado unitario no puede deducirse de los signilicados de las partes (v.gr., sacar partido, abrir boca, venir a cuento, sacar de quicio, etc.)

${ }^{26}$ En el ámbito del francés Bernard (1974) opone locuciones verbales ariculadas a locuciones verbales no arriculadas en función de la presencia o ausencia de actualizadores y modificadores, respectivamente.
} 
fijación de la misma». No obstante, no conviene obviar que en algunos casos existe la posibilidad de alternancia entre ausencia de actualizadores y modilïcadores y presencia de estos, tal y como ilustran los complejos:

(16) a. Dar besos / Le dio tres besos

b. Tener en cuenta/ Tener muy en cuenta

c. Tener hambre (sed, miedo) / Tener mucha hambre (sed, miedo)

d. Tener en consideración / Tener en buena consideración / Tener en una gran consideración

c. Hacer hincapié / Hacer especial hincapié

f. Hacer caso / Hacer algún caso / Hacer ningún caso / Hacer poco caso / Hacer muy poco caso

g. Hacer mención / Hacer una mención especial / Hacer especial mención

Teniendo en cuenta el comportamiento de estas estructuras (vid. infra), y con el lin de establecer distinciones graduales o jerarquías en el ámbito de las formas complejas, es muy probable que debamos distinguir entre modificadores del tipo de muy ((16b), (16f)), especial ((16e) y (16g)), poco $((161))$, gran $((16 \mathrm{~d}))$ y buena $((16 \mathrm{~d}))$ y actualizadores de la naturaleza de tres $((16 \mathrm{a}))$ y una $((16 \mathrm{~d}),(16 \mathrm{~g}))$. Los primeros adoptan la posición prenominal típica de los modificadores explicativos o no restrictivos ${ }^{27}$, distribución asociada a una complementación cerrada o no cxtensiva frente al carácter más abierto de la modificación postnominal-, mientras que los segundos parecen encontrar explicación a través del valor actualizador propio de los determinantes.

Pese a la cxistencia de casos en los que el complejo incorpora delcrminantes (o modificadores), debemos destacar que la tendencia gencral es la ausencia de determinantes y que, en caso de que aparezcan, suelen pertenecer, como hemos indicado anteriormente, al tipo o subtipo de detcrminante de valor más general o menos marcado (artículo defïnido o indelínido, sobre todo el primero). Por su parte, los modificadores en gencral remiten a adjetivos calificativos, antepuestos o pospuestos a la entidad nominal, que designan una propiedad general, y no a los clasificadores que, además de estar vinculados exclusivamente a la posición postnominal y de introducir el sustantivo al que modifican en una clase

\footnotetext{
27 En los cjemplos anteriores, podemos comprobar que gran parte de los elementos que funcionan como modificadores (buena, gran, especial y poco) son adjetivos explicativos o cualitativos cuya función es atribuir al nombre una cualidad objetiva, no clasificadora (vid. inf $\mathrm{ra}$ ). Debemos constatar que los adjetivos explicativos pueden aparecer antepuestos o pospuestos a la entidad nominal a la que modifican.
} 
particular, restringen su significado estableciendo oposiciones semánticas concretas (v.gr., niño inglés / niño español $)^{28}$.

Así como los modificadores mencionados en las secuencias (16) (muy, buena, gran, especial y poco) no parecen contribuir a una interpretación no incorporada de los complejos en los que se incrustan ${ }^{29}$, las estructuras directas que admiten la interpolación de actualizadores aceptan con relativa naturalidad las pruebas transformacionales que hemos utilizado en este trabajo para demostrar el perfil complejo o autónomo, autónomo en este caso concreto, de las entidades nominales:

(17) a. ¿Qué le dio? Tres besos

b. ¿Le dio tres besos? Sí, se los dio

c. Lo que le dio fue tres besos ${ }^{30}$

(18) a. ¿Qué hizo? Una mención especial

b. ¿Hizo una mención especial? Sí, la hizo

c. Lo que hizo fue una mención especial

Incluso la interpolación de un modificador cuantificador como mucha favorece la interpretación no incorporada:

(19) a. ¿Qué tiene? Mucha hambre (sed, miedo)

b. ¿Tiene mucha hambre (sed, miedo)? Sí, la tiene

c. Lo que tiene es mucha hambre (sed, miedo)

Por otra parte, algunas de las consideradas formas incorporadas como dar una bofetada, echar la culpa, salir al paso o volver a las andadas no ofrecen la posibilidad de ausencia de actualizador - lo que, con toda probabilidad, indica que está lexicalizado- y otras como ir de vacaciones, ir a las manos, tener agallas o volver a las andadas fijan su componente nominal en el número plural y el género femenino, número y género que pierden su valor referencial ya que no tienen posibilidad de contrastar y oponerse al singular:

(20) a. * Ir de vacación

b. *Ir a la mano

\footnotetext{
28 A cste respecto, cli. Bosque (1993: 35) y Hernanz y Brucart (1987: 169-183).

24) Las lexías que los integran constituyen, por tanto, variantes lexemáticas, no invariantes, habida cuenta de que no alteran el significado de la lexía base. Las variaciones vienen dadas por las necesidades del discurso, cumpliendo la función semántica que las caracteriza en la técnica libre del discurso (Zuluaga, 1975: 239-240).

${ }^{30}$ Cuando dar se combina con un sustantivo [+discontinuo] y [+concreto] del tipo de besos la naturalcza menos incorporada de esta entidad es evidente con respecto al uso claramente incorporado de ese mismo verbo con entidades nominales de perfil [+continuo] y [+abstracto] de la naturaleza de miedo (vid. supra secuencia (5)).
} 

c. *Tener agalla
d. *Volver a la andada

Si aplicamos las anteriores pruebas a estos complejos podremos comprobar que tan solo dar una bofetada y tener agallas (vid. supra (9)) las toleran con mayor o menor naturalidad:

(21) a. ¿Qué le dio? Una bofetada

b. ¿Le dio una bofetada? Sí, se la dio

c. Lo que le dio fue una bofetada

En definitiva, ante estos parámetros clasificatorios o delimitadores de los componentes complejos, nos encontramos con que tan solo parte de estos responden positivamente a los tres parámetros. Por ejemplo, formas descompuestas como poner de relieve, sacar a colación o poner en tela de juicio ilustran el comportamiento prototípico de formas lexicalizadas: son más o menos opacas en la vertiente nocional (menos poner de relieve que sacar a colación y poner en tela de juicio), no permiten análisis sintáctico individualizado de sus componentes $y$, finalmente, no toleran la presencia de actualizadores o modificadores:

(22) a. Poner de relieve $\rightarrow$ *Poner de eso (de ello) / *Poner del/ un relieve/ "Poner muy de relieve

b. Sacar a colación $\rightarrow *$ Sacar a eso (a ello) / *Sacar a la/una colación, *Sacar muy a colación

c. Poner en tela de juicio $\rightarrow *$ Poner en eso (en ello) / *Poner en la/una tela de juicio,"*Poner muy en tela de juicio

Sin embargo, tal y como hemos visto con anterioridad, determinadas formas descompuestas se muestran más flexibles con respecto a cualquiera de los tres criterios o en relación con los tres simultáneamente. Así, las formas complejas que constan de verbo y nombre como tener miedo, tener hambre, tener sed, hacer mención, hacer hincapié o formas compuestas de verbo y estructura prepositiva como tener en consideración admiten la interpolación de actualizadores o modificadores (vid. supra (16)).

Además, parte de las estructuras directas permite con «relativa naturalidad» la sustitución pronominal propia del complemento directo (aunque no la conversión a pasiva) y la estructura ecuacional (cfr. supra (7), (8), (9)):

(23) a. ¿Tienes sueño? Sí, lo tengo / Lo que tengo es sueño / "Sueño es tenido por mí

b. ¿Tienes miedo? Sí, lo tengo / Lo que tengo es miedo / Miedo es tenido por mí 
c. ¿Tu hermano tiene agallas? Sí, las tiene / Lo que tiene son agallas /

*Agallas son tenidas por tu hermano,

to que evidencia que los componentes nominales mantienen cierta independencia sintáctica con respecto al verbo o, por lo menos, el grado de incorporación o lexicalización es menor que el que podemos detectar en otros complejos verbo-nominales como:

(24) a. Hacer alusión

b. Hacer referencia

c. Hacer hincapié

d. Hacer mención

e. Hacer tabla rasa

f. Dar rienda suelta

g. Dar pic,

en los que la sustitución pronominal en algunas ocasiones es muy forzada, posiblemente agramatical, claramente agramatical en otras y la ecuacional resulta siempre agramatical:

(25) al ¿Hiciste alusión a este hecho? ?/* Sí, la hice / *Lo que hiciste fue alusión a este hecho

b. ¿Hiciste referencia a este aspecto? ?/* Sí, la hice / Lo que hiciste fue referencia a este aspecto

c. ¿Hiciste hincapié en este asunto? ?/* Sí, lo hice / Lo que hiciste fue hincapié en este asunto

d. ¿Hizo mención de este asunto? ?/* Sí, la hizo /* Lo que hizo luc mención de este asunto

c. ¿Hizo tabla rasa de este asunto?, Sí, *la hizo $/$ *Lo que hizo fue tabla rasa de este asunto

f. ¿Dio rienda suelta a sus sentimientos? Sí, *la dio / "Lo que dio lue ricnda suelta a sus sentimientos

g. ¿Diste pie a esta relación? Sí, *lo di / *Lo que diste fue pie a esta relación

La posibilidad de que, al menos, algunos de estos complejos admitan la sustitución pronominal —negada, no obstante, por algunos investigadores (cifr. García-Migucl, 1995: 104; Moreno Cabrera, 1991: 496-497)— nos ratifica en la idea de que uno de los requisitos esenciales de las formas descompuestas, el que la entidad nominal deje de ocupar la posición del complemento directo, no funciona de forma tajante en estos casos $\mathrm{y}$, consecuentemente, constituye un indicio de que, como mínimo, existen gradaciones en el proceso de incorporación. En el apartado siguiente vercmos que el hecho de que la sustitución pronominal vaya arropada por 
las prucbas interrogativa $y / 0$ ecuacional, posiblemente indica la cxistencia de diferentes grados en el proceso de incorporación sintáctica e incorporación scmántica.

Por otra parte, si esa entidad nominal dejara de ocupar el hueco del complemento directo este pasaría a ser cubierto por otras funciones, algo que no sucede en el español, dado que la incorporación de otras entidades en la predicación o bien da lugar a un modificador de la frase nominal o bien implica la introducción de un complemento indirecto:

\section{(26) a. Hacer mención de algo \\ b. Darlc besos a alguien}

\section{Incorporación semántica e incorporación sintáctica}

El proceso de incorporación que se puede detectar en lenguas como el nahua, iai, esquimal o chucoto ${ }^{31}$, en el seno de las que existe incorporación morfológica, adcmás de fonética ${ }^{32}$, del sustantivo con respecto a la entidad verbal a la que se une, no lo encontraremos nunca en una lengua como el español. En esta lengua, o en otras como el inglés o el francés, se opera, en todo caso, una incorporación semántica y/o sintáctica en la que el constituyente nominal pasa a formar una unidad sintagmática con la entidad verbal, aunque sigue conservando autonomía fonética, accntual y morfológica con pérdida, no obstante, de las propiedades sintácticas y morfológicas lípicas de las funciones sintácticas complemento directo o prepositivo.

En algunas ocasiones ni siquiera llega a haber orden fijo en el interior de la forma incorporada:

(27) No tengo miedo - Miedo no tengo,

y esta puede permitir interpolación de, al menos, modificadores (vid. supra (16)), algo impensable en el seno de la palabra o en el ámbito de las formas incorporadas en el nivel fonético, además de en el morfológico.

La ausencia de los rasgos típicos de los procesos de incorporación fonética, morlológica y sintáctica en una lengua como el español ha sido cvidenciada por los investigadores en estrecha rclación con la existencia

\footnotetext{
"Vid. García-Miguel (1995: 98-101), Lazard (1984: 276), Mithun (1984) y Moreno Cabrera (199I: 494).

32 Por cjemplo, algunas lenguas que poseen el mecanismo de incorporación fonética y morfológica exigen «armonía vocálica» en el interior de la unidad compleja y la entidad nominal pierde los morfemas que tiene en las configuraciones libres.
} 
indiscutible en nuestra lengua de incorporación semántica, pero con la intuición de que conviene establecer grados en el marco de la incorporación sintáctica.

Con anterioridad, hemos comprobado que formas descompuestas como dar una bofetada (vid. supra (21)), tener hambre/sed (vid. supra (19)), tener agallas (vid. supra (9)) o hacer una mención especial (vid. supra (18)) admiten con «relativa» naturalidad las tres pruebas que hemos habilitado para constatar el perfil complejo o autónomo de sus componentes nominales o prepositivo-nominales; en contrapartida, complejos de la naturaleza de dar miedo (vid. supra (5)), hacer alusión (vid. supra (25a)), hacer hincapié (vid. supra (25c)), hacer tabla rasa (vid. supra (25e)) o dar rienda suelta (vid. supra (25f)) no toleran ninguna de las tres pruebas transformacionales.

Partiendo de esta línea evolutiva, decreciente en cuanto al grado de autonomía sintáctica, parece que el primer grupo responde al proceso de incorporación semántica pero no tanto al mecanismo de incorporación sintáctica, mientras que el segundo grupo, sin dar ningún lugar a dudas, sería el representante genuino de la incorporación semántica y de la sintáctica ${ }^{33}$.

Sin embargo, otra posibilidad interpretativa referente a la prueba de la sustitución pronominal es que esta no resulta relevante - como opinan algunos investigadores-, o como mínimo es discutible, y que esa «aparente» aceptabilidad la debamos atribuir a un «acto reflejo estructural» por analogía con las configuraciones transitivas que configuran los componentes verbales de esos complejos sintagmáticos:

\section{(28) a. Tengo mucho dinero $\rightarrow$ Lo tengo \\ b. Le di la muñeca a la niña $\rightarrow$ Se la di}

No obstante, la autonomía sintáctica del constituyente nominal parece al menos discutible cuando la sustitución pronominal se ve ratificada por las construcciones interrogativa y ecuacional que, a través de un mecanismo nítido de extracción, muestran la pervivencia del hueco funcional que, cuando menos, no parece haber sido absorbido por la entidad verbal de forma lajante (vid. supra (8) y (9)).

\footnotetext{
${ }^{33}$ Queremos hacer notar que esta gradación en el estrato sintáctico también se puede, y realmente se debe, extrapolar al parámetro nocional, de tal forma que, en relación con el nivel sintáctico, es csperable que existan grados en la incorporación semántica asociados al perfil más o menos opaco de los constituyentes del complejo. En este sentido, parece que en las formas descompuestas con incorporación sintáctica nula o atenuada ( $v . g r$. , tener miedo o dar una bofetada) los componentes nominales, además de los verbales, hacen gala de un contenido más cercano al literal o denotativo que el que los mismos componentes poseen en las formas descompucstas con incorporación sintáctica indiscutible ( $v$.gr., hacer tabla rasa o dar rienda stelti).
} 
Esta inestabilidad en el área de las formas \pm incorporadas dibuja una plataforma lingüística gradual en la que las formas claramente incorporadas en el nivel sintáctico-semántico y las que ofrecen una incorporación clara tan solo en el parámetro nocional se reparten áreas configuracionales más o menos consolidadas en el plano léxico y en el sintáctico. Esta plataforma gradual relleja una situación de tensión entre dos tendencias lingüísticas opuestas, la correspondiente a un enfoque sintético y la representante de un punto de vista analítico, tendencias que marcan un comportamiento lingüístico vivo y en pleno movimiento o fluctuación a caballo entre la sintaxis, la semántica y la morfología.

\section{Caracterización de formas descompuestas indirectas}

En este apartado nos proponemos abordar formas descompuestas indirectas integradas por verbo de movimiento y entidad prepositivonominal, con el objetivo de individualizar las propiedades generales que las caractcrizan y de establecer contraste entre estas formas complejas y las formas descompuestas directas que hemos descrito en los dos primeros apartados.

Para cllo se ha tomado como punto de referencia el Archivo de textos hispánicos de la Universidad de Santiago de Compostela (ARTHUS) almacenado cn una Base de datos sintácticos $(B D S)^{34}$, y se han scleccionado verbos de movimiento que conforman lexías indirectas con cotas de uso muy altas como entrar, poner, sacar y salir y otros, menos frecuentes en cste tipo de cstructuras, como echar, ir, venir, meter, pasar, volver, llevar y caer $^{35}$ :

CALiR: cncima, cn la cuenta (de), en pecado, en saco roto.

I:CHAR(SI:): abajo, atrás, encima, a [la] broma, a [las] espaldas, a pique, de menos, cn cara, en falta, por tierra.

ENTRAR: en acción, en ambiente, en calor, en combate (con), en colisión (con), en conllicto (con), en contacto [directo] (con), en contradicción (con), cn convalecencia, en declinación, en descomposición, en detalles, en diálogo (con), en ebullición, en explicaciones, en funcionamiento, en jucgo, en

\footnotetext{
3. Ambos forman parte del proyecto de investigación «Estructura de la cláusula y régimen verbal en español», cuyo investigador principal es Guillermo Rojo, financiado por la Xunta de Galicia (XUGA 82710088) y el Ministerio de Educación y Cicncia (PB90-0376).

35 Queremos hacer notar que la alternancia entre presencia y ausencia de detcrminante o modificador se marea mediante corchetes. Asimismo se utilizan los eorchetes para señalar las posibles variantes de las lexías, en tanto que los paréntesis indican la preposición que suclen regir tales lexías.
} 
materia, en proceso, en razón, en [vías de] regresión, en relación (con), en religión, en vías de solución, en vigor.

IR(SL): adelante, a pique, a las manos, a lo styo [a lo mío/lo tuyo/lo nuestro/lo vucstro], de vacaciones, en aumento, en busca (de) [en mi/tu/su busca], por las ramas.

L.LiV $\wedge$ : a cabo, adelante, a [buen] término, a la práctica.

METER(SI): en camisas de once varas, en cintura, en un berenjenal, en un [buen] lío, en vereda.

PNSAR: de largo, por alto.

PONER(SB): a prueba, al alcance (de) [a mi/tu/su alcance], a disposición (de) [a $\mathrm{mi} / \mathrm{tu} / \mathrm{su}$ disposiciónl, a salvo, al teléfono, de acuerdo (con), de maniliesto, de modia, de relieve, en camino, en duda, en entredicho, en escena, en evidencia, en luncionamiento, en juego, en manos (de) [en mis/tus/sus manos], en marcha, en tela de juicio.

SACAR(St:): a colación, adelante, a flor, a flote, a [la] luz, a relucir, a superficic, de cuidado, de la cabeza, de las casillas [de mis/tus/sus casillas], de madre, de onda, de quicio, en consecuencia, en limpio.

SALIR: adelante, al encuentro [a mi/tu/su encuentro], a llote, a la luz, a la superficie, al paso (de), con la suya [con la tuya/la mía/la nuestra/la vuestra], de cuclas, de las manos, del paso, por la tangente.

VENIR(SI): abajo, a cuento, a mano, a menos, a la boca, a la cabeza, al pelo, al suelo, de bruces, encima, en gana.

VOIVIR: a la carga, a la memoria [a mi/tu/su memoria], a la mente la $\mathrm{mi} / \mathrm{tu} / \mathrm{su}$ mentel, a las andadas, a las mientes, al recuerdo, atrás.

Se trala de verbos soporte, ligeros o livianos que han perdido el significado recto de movimiento o desplazamiento a favor de una dimensión abstracta que, como veremos con posterioridad, se halla vinculada a valores cxpresivos o modales fundamentalmente y, en ocasiones, aspectuales.

Quercmos destacar que la mayor parte de los verbos de movimiento que conforman lexías complejas pertenecen a la clase léxica y sintácticosemántica verbos de desplazamiento y no a la categoría de los verbos que denotan modo de desplazamiento, verbos de la naturaleza de andar, cominar, correr; arrastrar(se) o saltar ${ }^{36}$. Esta tendencia parece cstar asociada al índice de frecuencia y polivalencia de que hacen gala los verbos de desplazamicnto del tipo de $i r$, venir, llevar o volver, propiedades (la de la liecucncia y polivalencia) que reflejan la versatilidad construccional de tales entidades materializada a través de la conformación de distintas estructuras: perifrásticas (las tradicionales perífrasis verbales), lexemáticas (formas descompuestas como las abordadas en este trabajo), locativas (usos rectos de

\footnotetext{
3. Dado que este no es cl lugar propicio para desarrollar la oposición léxica y sintácticosemántica verbos de desplazamiento / verbos de modo de desplazamiento, remitimos al lector al trabajo de Ciluentes Honrubia (1988-1989).
} 
desplazamiento de la naturaleza de Fue a Valencia) y atributivas (estructuras de predicativo del tipo de Anda loco).

Estas entidades verbales se unen a preposiciones livianas ${ }^{37}$ como $a$, en y de que también se encuentran inmersas en un proceso de deslexicalización y gramaticalización. Ambos componentes, el verbal y el prepositivo, están estrechamente cohesionados tanto en el uso recto de desplazamiento como en el figurado ${ }^{38}$ de las lexías complejas, dando lugar en estas últimas a construcciones icónicas que canalizan valores aspectuales como el incoativo, que remite al inicio de la acción:
(29) a. Entrar en acción
b. Entrar en combate
c. Entrar en contacto
(1. Poner en funcionamiento
c. Poner en marcha
1. Poner en camino
g. Salir al paso,

el progresivo que, como su mismo nombre indica, codifica un valor de duración o continuidad:
(30) a. Venir a menos
b. Ir cn aumento,

cl reitcrativo (repetición del proceso verbal):
(31) ¿l. Volver a las andadas
b. Volver a la carga,

\footnotetext{
${ }^{37}$ Estas preposiciones son las que ofrecen un mayor índice de frecuencia tanto en los usos rectos como en los ligurados pertenccientes a las formas descompuestas. Conviene subrayar que las preposiciones que predominan en ambas tipologías construccionales son en y $a$, preposiciones de valor locativo-prospectivo frente al uso menos extendido de la preposición de polo negativo o eferencial: de.

${ }^{38}$ El significado verbal y prepositivo de estas lexías complejas puede ser explicado a través de un mecanismo derivacional o metafórico con respecto a los usos rectos de los verbos de movimiento. De hecho, en ambas tipologías construccionales se mantiene el mismo verbo y la misma preposición como mecanismo formal que sirve de puente formal y semántico, aun cuando se haya operado un proceso metaforizador de transformación nocional y sintácticoformal. Por tanto, la plataforma formal locativa (prepositiva o adverbial) es la que constituye el punto de relerencia para la fijación formal y funcional. De hecho, la mayor parte de las lexías abordadas en este apartado están integradas por verbo + preposición + sustantivo (v.gr., llevar a cabo, entrar en combale, ir en ammento) y, en menor proporción, por verbo + adverbio $(v, g$, ir adelante, renirse abajo), verbo + preposición + adverbio (v.gr., echar de menos), verbo + preposición + adjetivo (v.gr., pasar de largo, sacar en limpio) y verbo + preposición + artículo + pronombre (v.gr., ir alo suyo).
} 
o, simplemente, valores expresivos que se corresponden con un mecanismo analítico-descriptivo que entra en contraste directo con verbos simples:

(32) a. Poner en evidencia

b. Echar en falta

c. Venir a cuento

d. Sacar en consecuencia

Según Masullo (1996: 175):

En principio, los verbos y preposiciones livianas deben analizarse como categorías funcionales. En primer lugar, no asignan roles temáticos; en segundo lugar, los predicados livianos pueden verse como functores que convierten una categoría gramatical en otra. Por ejemplo, hacer en hacer uso convierte un sustantivo en verbo, y, por su parte, las preposiciones livianas pueden convertir un nombre en adjetivo (en paz $=$ (ranquilo) 0 en un elemento adverbial $($ en conjunto $=$ conjuntamente); otras veces, tienen una función aspectual (en funcionamiento = funcionando; en llamas = quemándose; de viaje $=$ viajando, etc. $)$.

Si establecemos contraste entre las formas descompuestas directas y las indirectas con respecto a los tres niveles a los que hemos recurrido en este trabajo, el semántico, el sintáctico y el morfológico, podremos comprobar que existen diferencias ostensibles entre ambas tipologías formales.

Desde el parámetro nocional constatamos que las formas indirectas remiten a un proceso de metaforización que desemantiza los componentes verbal y prepositivo-nominal, dando lugar más sistemáticamente que las estructuras directas a construcciones de significado figurado u opaco que conservan nada o muy poco del contenido literal que poseen verbo y entidad prepositivo-nominal en las configuraciones rectas:

(33) a. Sacar a colación

b. Sacar de quicio

c. Volver a las andadas

d. Caer en la cuenta

e. Echar a pique

i. Llevar a cabo

g. Meterse en camisas de once varas

El cstrato sintáctico brilla por su ausencia en el sentido de que no existen, en el ámbito de las configuraciones indirectas, las oscilaciones sintácticas que hemos detectado en construcciones directas del tipo de tener agallas, tener miedo o dar una bofetada, antes bien las lexías indirectas 
remiten a un proceso de incorporación sintáctica nítido que propicia un proceso recesivo en el nivel actancial:

(34) a. Saqué el perro a la calle (Saqué el perro ahí/allí) $\rightarrow$ Saqué a colación ese asunto ("Lo saqué a eso/ahí)

b. Volví a casa muy tarde (Volví aquí/ahíallí muy tarde) $\rightarrow$ Volví a las andadas ("Volví a eso/ahî)

c. Cayó en plena calle (Cayó aquí/ahí/allí) $\rightarrow$ Cayó en la cuenta de que había quedado contigo ("Cayó en eso/ahí)

d. Eché la ropa en la lavadora (La eché aquí/ahí/allí) $\rightarrow$ Eché a pique este asunto (*Lo eché aquí/ahí/a eso)

Y, por último, el nivel morfológico evidencia que en gran parte de las formas indirectas que aquí abordamos se da una fijación formal que no tolera la incursión de modificadores y actualizadores:

(35) a. Sacar a colación $\rightarrow$ *Sacar a la/una colación $\rightarrow$ *Sacar a cspecial/gran colación

b. Volver a las andadas $\rightarrow *$ Volver a sus/tus andadas $\rightarrow *$ Volver a las cspeciales/grandes andadas

c. Caer en la cuenta $\rightarrow$ *Caer en su/mi cuenta $\rightarrow$ * Caer en la especial/gran cuenta

d. Echar a pique $\rightarrow$ *Echar al/su/mi pique $\rightarrow$ *Echar al especial/gran pique

En los casos de la naturaleza de:

(36) a. Venir en mi/tu/su ayuda

b. Sacar de las/mis/tus/sus casillas ${ }^{39}$

c. Entrar en contacto [directo]

d. Llevar a [buen] término,

en los que, aparentemente, tienen cabida determinantes y modificadores, debemos partir de la premisa de que no se trata de determinantes y

\footnotetext{
${ }^{39}$ En relación con estas estructuras conviene subrayar que su naturaleza «variable» es relativa habida cuenta de que no aumenta ni disminuye el número de sus constituyentes sino que se da intercambio en el paradigma de los determinantes. En opinión de Zuluaga (1975: 239-240) «la casilla libre es ocupada por elementos no fijos cada vez que Ja expresión es utilizada en el hablar. Estos, ciertamente, se encuentran dentro de límites semánticos (p.ej., un campo o una clase $[. . . \mid$ ) determinables en cada caso concreto; p. ej., situación, expresada mediante los situadores posesivos mis, tus, sus, nuestras, en el caso de a ... anchas, y actualización o cuantificación [...], expresadas mediante el artículo la o mediante cuantificadores diversos como una, varias, muchas, dos, etc., respectivamente, en el caso de pasar... noche(s) en velas.
} 
modilicadores «reales» ${ }^{40}$, es decir, de unidades que siguen las reglas de estructuración y/o combinación de los determinantes y modificadores prototípicos, y de que en las estructuras de la naturaleza de (36c) y (36d) estamos ante variantes estilísticas «enfatizadoras» del valor semántico del sustantivo mediante la introducción de un adjetivo explicativo que no establece oposición con respecto a fórmulas del tipo de entrar en contacto indirecto y llevar a mal término, aun cuando se puede prescindir de sus modificadores $\sin$ vulnerar la naturaleza lexemática de la estructura.

Asimismo, queremos constatar la especialización que suponen ciertas formas descompuestas indirectas en lo que concierne a la entidad prepositiva, especialización paralela a la que se puede detectar en los usos locativos o rectos de los verbos que se combinan con tales preposiciones ( $v . g r$, caer en, entrar en, meter(se) en), frente al uso menos especializado y, consecuentemente más variopinto, verificado en las lexías de verbos como ir ( $a$, de, en, por), poner (se) (a, de, en) y $\operatorname{sacar}(a$, de, en) que ofrecen tal variabilidad formal en las construcciones autónomas.

En delinitiva, las propiedades que hemos extraído de la aplicación de los tres niveles analíticos empleados en la caracterización de las formas descompuestas nos confïma en la idea de que los complejos indirectos iienen una naturaleza más prototípicamente compleja que determinadas formas directas, puesto que se vinculan a propiedades como opacidad nocional, ausencia de autonomía sintáctica e inmovilismo formal; propiedades que, según hemos visto en los anteriores apartados, certifican la naturaleza incorporada de tales entidades tanto en el nivel semántico como en el sintáctico.

Las razones que sustentan esta naturaleza fija posiblemente son de perfil léxico y sintáctico. Es altamente probable que en estas construcciones indirectas detectemos un grado de fijación superior al de las directas porque se da una doble vía de fijación o lexicalización, dado que en un primer momento se opera la lexicalización de la preposición y del nombre (sustantivo, adjetivo, adverbio o pronombre) que la sigue y en una segunda fasc la lexicalización afecta al verbo y al complejo prepositivo-nominal. Ese primer momento lexicalizador estaría vinculado a un complemento modal, proceso modal generado por las preposiciones que tienen la capacidad de convertir un nombre en un adverbio de modo (vid. Masullo, 1996: 175) y, consecuentemente, de alejar el nombre del marco denotativo-referencial que lo caracteriza en las estructuras rectas. Por ejemplo, con respecto a una lexía

\footnotetext{
4i) Como ya hemos mencionado con anterioridad, el determinante que aparece en formas descompuestas del lipo de (36a) y (36b) está absolutamente lexicalizado, por lo que no conserva la dimensión actualizadora propia del uso no marcado de determinantes como el artículo definido o indefinido, los posesivos y los demostrativos.
} 
como echar de menos tendríamos una primera fase lexicalizadora en la que la estructura prepositiva de menos adquiriría un valor modal para acto seguido fusionarse con la entidad verbal y dar lugar, definitivamente, al valor unitario que encarna tal forma descompuesta.

Esta doble vía de incorporación es la que canaliza una plataforma lingüística cstable, fija o sistemática, al tiempo que icónica, en el ámbito de las formas descompucstas indirectas.

En contrapartida, las formas descompuestas directas se asientan en el parámetro de la transitividad ligado a un mecanismo lingüístico gradual, carácter gradual que da entrada a diferentes niveles de incorporación sintáctica que no permiten distinguir con una nitidez indiscutible configuraciones transitivas de configuraciones incorporadas. Se trata de una plataforma gramaticalizada ${ }^{41}$ que tolera la incursión de variaciones formales asociadas a actualizadores y modificadores ${ }^{42}$; y estas variaciones formales, entre otras de perfil nocional, son las que impiden una fijación sintácticoformal de naluralezal unívoca.

Por su parte, las estructuras prepositivo-nominales bloquean, en líncas generales, la expansión a través de modificadores o de actualizadores; en particular, la preposición parece impedir la articulación y expansión del componente nominal en el marco de una estructura prepositiva cerrada que establece una relación indirecta con el verbo y que, en cierta medida, independiza el componente nominal de la estructura sintáctica en general, en el sentido de que no permite expansión morfológica o sintáctica.

En lo que respecta a la contribución de las formas descompuestas al ámbito del léxico, simplemente queremos constatar que, como ya habían indicado Dubsky (1963: 46) y Harvey (1968: 239), la existencia de los complejos directos $\mathrm{c}$ indirectos en general, y de los indirectos en particular, no signilica que el léxico español sea pobre o deficitario y recurra a la creación de nucvas entidades con el fin de suplir lagunas léxicas; más bien apunta al carácter creativo, en el seno de campos léxicos abiertos, que ofrece alternativas sintéticas (verbos simples) y alternativas analíticas (formas descompuestas, además de perífrasis verbales).

Así como las perífrasis verbales tradicionales incorporan contenidos temporales, aspectuales y modales de los que carecen las formas verbales

\footnotetext{
"Utilizamos el término gramaticalizado con el significado que to atribuye Garcít-Miguel (1995: 41-46), de tall forma que entendemos por funciones sintácticas gramaticalizadas aquellas vinculadis a mecanismos formales fijos como la concordancia morfémica (la existente entre verbo y sujeto) y la concordancia objetiva que encarnan el complemento directo y el indirecto, adeniás de a mecanismos semánticos como la homogeneización de variantes semánticas.

12 Así como a variaciones nocionales como el aspecto y el estado de cosas que instaura la predicación (1.gr., activo o estativo) y que aquí no abordamos (vid. Hopper y Thompson, 1980: 252).
} 
simples, las entidades descompuestas indirectas que hemos abordado en este apartado codifican contenidos aspectuales (vid. supra (30), (31) y (32)):

(37) a. Entrar en acción

b. Entrar cn combate

c. Salir al paso

d. Poner en marcha,

o contenidos modales:

(38) a. Poner en duda

b. Venir en ayuda

c. Llevar a cabo

que establecen un contraste directo con la dimensión significativa aportada por los verbos simples, esto es, ilustran una dimensión de descomposición descriptiva y más expresiva que la ofrecida por las entidades simples, trasluciendo un enfoque icónico y plástico.

\section{Recapitulación}

El estudio de determinadas formas descompuestas directas e indirectas ha pucsto de manifiesto que existe una serie de principios o rasgos generales que se les puede atribuir de forma genérica, aun cuando no son pocas las variaciones que no encuentran explicación en un marco descriptivo tajante o categórico, además de excesivamente global. Retomando las palabras de Corpas Pastor (1997: 31) referidas a las unidades fraseológicas en general, podcmos concluir que:

las unidades fraseológicas [...] se dividen en grupos, siguiendo la escala de mayor a menor, según el grado en el que presenten las características $[\ldots]$ habilitadas para su delimitación (cursiva nuestra). Cada grupo forma un continutum en el que se distinguen puntos sobresalientes, que marcan los clementos más claros, y puntos intermedios que indican categorías intermedias.

En este sentido, hemos combinado un prisma general (macrosistema), que toma en consideración las propiedades que se suelen imponer en los complejos sintagmáticos que hemos analizado, con un enfoque particular (microsistema) que se centra en el contraste entre los diferentes componentes que forman complejo con la misma entidad verbal. 
Entre las propiedades que han contribuido a perfilar las formas descompuestas, aparte de las de naturaleza nocional y sintáctica, se encuentran las ubicadas en el estrato morfológico, en particular la presencia/ausencia de actualizadores y modificadores. Hemos constatado que la presencia de actualizadores como un y tres y modificadores como mucho debilita, en ocasiones al menos, el proceso de incorporación sintáctica ${ }^{4.3}$, mientras que modificadores del tipo de buena, gran, especial, muy y poco no parecen adquirir la relevancia de tales elementos para minar cl carácter unitario de las formas descompuestas en las que se integran.

Con $\mathrm{cl}$ objetivo de mostrar de qué forma inciden esas variaciones en cl carácter más o menos incorporado de las formas descompuestas, hemos utilizado una scric de tests transformacionales, con tradición en los trabajos que versan sobre este tema, que nos aportan, como mínimo, una serie de indicios pertinentes para la descripción de las entidades complejas.

En esta línea de investigación, hemos comprobado que, así como existen formas descompucstas directas que responden a las pruebas o tests transformacionales con los que se pretende probar su naturaleza compleja, dando lugar, consecuentemente, a un proceso de incorporación sintácticosemántica evidente, otras no responden de forma unívoca a tales tests, lo que, posiblemente, determina una incorporación exclusivamente semántica o la existencia de grados en el marco de la incorporación sintáctica.

Esta óptica gradual es patente en las formas directas y no en las indirectas. En estas últimas hemos verificado que el grado de fijación léxica y sintáctico-scmántica es superior al que hemos detectado en las entidades complcjas directas, comportamiento que hemos vinculado a la existencia de una doble vía de lexicalización que refuerza la naturaleza fija y estercotipada de estas entidades y al carácter cerrado, de bloque compacto que apenas tolera expansión de actualizadores y modificadores, que impone la conliguración prepositiva.

\footnotetext{
${ }^{4.3}$ Este comportamiento Io hemos visto en las ejemplos de la serie (16). No obstante, en casos cono:

a. Hacer caso / Hacer ningún caso / Hacer algún caso

b. Tener en consideración/ Tener en una gran consideración

la presencia de los indefinidos no fomenta la individualidad sintáctico-semántica del componente nominal o prepositivo-nominal, lo que, probablemente, indica que son entidades relativamente lijas y lexicalizadas.
} 


\section{Referencias bibliográficas:}

Alcina Franch, J. y J. M. Blecua (1975): Gramática española, Barcelona: Aricl.

Baker, M. C. (1988): Incorporation. A Theory of Grammatical Function Changing, Chicago \& Londres: The University of Chicago Press.

Bcrnard, G. (1974): «Les locutions verbales françaises», La Linguistique, V/10-2, págs. 5-17.

Bosque, I. (1993): «Sobre las diferencias entre los adjetivos relacionales y los calilïcativos», Revista Argentina de Lingüística, 9 (1-2), págs. 9-48.

Bosque, I. (1996): «Por qué determinados sustantivos no son sustantivos determinados. Repaso y balance», en I. Bosque (ed.): El Sustantivo sin determinación. La ausencia de determinante en la lengua española, Madrid: Visor Libros, págs. 13-119.

Cano Aguilar, R. (1981): Estructuras sintácticas transitivas en el español actual, Madrid: Gredos.

Cano Aguilar, R. (1984): «Cambios de construcción verbal en cspañol clásico», BRAE, LXIV, págs. 203-255.

Cano Aguilar, R. (1985): «Sobre el régimen de las oraciones completivas en español clásico», Philologica Hispaniensia in honorem Manuel Alvar, vol. II, Madrid: Gredos, págs. 81-93.

Castillo Carballo, M. A. (1997-1998): «El concepto de unidad fraseológica», Revista de Lexicografía, IV, Universidade da Coruña, págs. 67-79.

Cifuentes Honrubia, J. L. (1988-1989): «Sobre las construcciones locales en español», Estudios de Lingiiística, 5, págs. 145-181.

Corpas Pastor, G. (1997): Manual de fraseología española, Madrid: Gredos.

Coseriu, E. (1981): Lecciones de Lingiiistica general, Madrid: Gredos.

Dubsky, J. (1963): «Formas descompuestas en el español antiguo», RFE, XL.VI, págs. 31-48.

Dubsky, J. (1965): «Intercambio de componentes en las formas descompuestas españolas», Bulletin Hispanique, 67, págs. 343-352.

Dubsky, J. (1966): «Composition, derivátion et décomposition», Lingua, 16, págs. 190-198.

Dubsky, J. (1974): «Estructuración semántica de modismos», Iberoamericana praguensia, VIII, págs. 51-58.

Folgar Fariña, C. (1988): «Sintaxis y semántica de enviar en español medicval», Verba, 15, págs. 289-322.

Gaatone, D. (1981): «Les «locutions verbales»: Pour quoi faire?», Revue romane, 16, págs. 49-73. 
García-Miguel, J. M. (1995): Las relaciones gramaticales entre predicado y participantes, Lalia, 2 (Series Maior): Universidade de Santiago de Compostela.

Gross, M. (1982): «Une classification des phrases «figécs» du français», cn P. Attal y C. Müllor (eds.): De la syntaxe à la pragmatique, Amsterdam, Benjamins, págs. 141-180.

Guillet, A. (1986): «Représentation des distributions dans un LexiqueGrammairc», Langue Française, 69, págs. 85-107.

Harvey, L. P. (1968): «Una nota sobre las «formas descompuestas en el cspañol antiguo»», RFE, 51, págs. 239-242.

Hernanz, M. L. y J. M. Brucart (1987): La sintaxis. 1. Principios teóricos. La oración simple, Barcelona: Crítica.

Hopper, P. J. y S. A. Thompson (1980): «Transitivity in Grammar and Discoursc», Language, 56/2, págs. 251-299.

Latard, G. (1984): «Actance Variations and Categories of the Object», en F. Plank (ed.): Objects, Londres: Academic Press, págs. 269-292.

Leclere, Ch. (1990): «Organisation du Lexique-Grammaire des verbes françaises», Langue Française, 87, págs. 112-122.

Mardirrussian, G. (1975): «Noun Incorporation in Universal Grammar», CLS, 11, págs. 383-389.

Masullo, P. J. (1996): «Los sintagmas nominales sin determinante: una propuesta incorporacionista», en I. Bosque (ed.): El Sustantivo sin determinación. La ausencia de determinante en la lengua española, Madrid: Visor Libros, págs. 169-200.

Melero, M. y O. Gracia (1990): «Construcciones de verbo soporte», Actas del Congreso de la Sociedad Española de Lingüística. XX aniversario, vol. II, Madrid: Gredos, págs. 653-667.

Menénder Pidal, R. (1944-46): Cantar de Mio Cid. Texto, gramática y voctibulcrio, 3 vols., Madrid: Espasa-Calpe.

Mithun, M. (1984): «The cvolution of noun incorporation», Language, 60/4, págs. 847-894.

Moreno Cabren, J. C. (1991): Curso universitario de linguiística general. Tomo I: Teoria de la gramática y sintaxis general, Madrid: Síntesis.

Moyse-Fauric, C. (1985): «Incorporation morphologique et incorporation syntaxique cn drchu», Actances, 1, págs. 125-133.

Polák, V. (1949-51): «La périphrase verbale des langues de L'Europe occidentale», Linguat, 2, págs. 64-73.

Ramos Ménder, M. (1989): «Formas descompucstas + cláusula completiva objeto en tres textos medicvales castellanos», Verba, 16, págs. 339-356.

Varcla, F. у H. Kubarth (1996): Diccionario fraseológico del español modemo, Madrid: Gredos. 
Wotjak, G. (1985): «Algunas observaciones acerca del significado de expresiones idiomáticas verbales en el español actual», Anuario de Linguiustica hispánica, 1, págs. 213-225.

Yllera, A. (1980): Sintaxis histórica del verbo español: las perifrasis medievales, Zaragoza: Universidad de Zaragoza.

Zuluaga, A. (1975): «La fijación fraseológica», Thesaurus, XXX/2, págs. $225-248$. 